\title{
Aisatsu as Phatic Communion (Tatemae) in the Daily Life of Japanese People
}

\author{
Ina Ika Pratita \\ Universitas Negeri Surabaya \\ Surabaya, Indonesia \\ inapratita@unesa.ac.id
}

\author{
Masilva Raynox Mael \\ Universitas Negeri Surabaya \\ Surabaya, Indonesia \\ masilvamael@unesa.ac.id
}

\author{
Didik Nurhadi \\ Universitas Negeri Surabaya \\ Surabaya, Indonesia \\ didiknurhadi@unesa.ac.id
}

\begin{abstract}
Aisatsu is seen as phatic communion (tatemae) in the daily life of Japanese People. There are norms applied in social life including the use of aisatsu (greetings) which is very important in Japan. Aisatsu can open one's heart and draw closer to the hearer when interacting as a phatic communion (tatemae). In the context of the Japanese language, aisatsu is often used when dealing with fellow humans (human relations) in the daily life of Japanese people. This article is a preliminary research regarding the use of aisatsu as phatic communion (tatemae) in the daily life of Japanese people. Aisatsu is define as an expression of praise, respect, encouragement, and others. The focus is the expression of the phatic communion itself which is placed on the context-social context. More details discuss about the types of aisatsu as a phatic communion including the phatic communion as greetings and pleasantries as a courtesy. It is aimed at the harmonization of the means to maintain and encourage social relations between speakers by using the language usage that is completely natural (naturally occurring language) and pervasive in the social context of Japanese culture.
\end{abstract}

Keywords - aisatsu; greetings; phatic communion; tatemae; japanese culture

\section{INTRODUCTION}

Geertz [1] says that to be a human means to become individual, in accordance with the cultural patterns that exist. In which empirically, it is a system created from the shape regularity and the direction or purpose of life. "Culture is a series of control mechanisms contained in the rules of society that govern behavior". Furthermore, the language of manifest classification system can be used to explore cultural practices in a society. The model of culture can be raised explicitly through the expression [2]. Language as a tool of communication is very essential in human life, i.e. to meet all the needs of one's life. In the use of language in societynonsense, it often encountered in the interaction. Furthermore, it is the power of language to solidarity and harmonization of the social community in the form of strategies determining the relationship of each other. Cultural value can also be obtained through this.
In the life of the Japanese people, the greetings which are often used in interaction with other people is very diverse. Aisatsu is important in Japan because Japanese people see and judge a person from how they greet other people properly. When Japanese meets someone, for example his neighbor or his contacts always mince words, this is a hallmark of Japanese culture that always pay attention to the human relations (human relations) which is very strong to show friendliness to someone or express respect. In general, aisatsu is a good media to maintain good relations among human beings.

As an opening, it is usually connected with the state of nature, for example weather [3]. As an example, when Japanese says, "Otenki desu ne (the weather is nice, isn't it?)", or during traveling, the terms used by Japanese is almost similar to Javanese people, for example with a neighbor that will go somewhere by saying "Follow ya?" and answered "nggeh". Then in the Japanese language, the spoken terms is "Odekake desu ka (do you want to go?)", and it is answered as "Hai (yes)", and so on.

The use of aisatsu as pleasantries is administered in everyday life by the people of Japan. This shows that aisatsu is a communication tool, a tool to cooperate with others, and a tool to identify yourself that is influencing and meaningful.

Aisatsu, according to Nihongo Kyouiku Gakkai in Nihongo Kyouiku Jiten [4], it is explained that aisatsu is a phrase that is answered with an expression of friendly, affectionate, or respectful in everyday life. Usually, most of the phrase has a specific shape such as "こんにちは"、"さようなら"

Aisatsu in Japan has shifted, especially among young children. Koyama [5] says that language is something alive and dynamic. Therefore, it is very reasonable and natural if it may disappear as the time goes by. This means that various phrases either associated with the culture of greetings or shifted in the meaning of the word and in daily use also undergo changes. 
According to Moeliono [6], compound words pleasantry has three meanings, namely (1) "customary manners, good karma association", (2) "a phrase used only to manners and not to convey information", and (3) "the use of phrases of the kind". In this dictionary, it is mentioned, for example, "Where are you going?" as the small talk that is spoken when someone meet with a friend, Then, the meaning of it becomes the object of analysis in linguistic. Customary manners, and etiquette are just a context object which is the target or result of the actions of it. It becomes the focus of the expression of the preamble itself which is placed on the context-social context.

\section{LITERATURE REVIEW}

\section{A. The Concept of Phatic Communion from Malinowski}

Ado is a marker of social in community life. Society Japanese life, in fact, was hard to imagine. The importance of the preamble is the same as the case with the importance of that language in general. Ado is the quintessence or the core mode to talk to the man. The concept of niceties of Phatic Communion introduced by the linguist Malinowski [7] in the field of linguistics. Phatic Communion or communication is the substitutions of the expression frozen, like hello, what's up, and others that do not have meaning in the sense to convey information but rather used to make social contact between the speaker or to avoid silence that may cause a sense of clumsy [8].

This opinion is in accordance with the concept stated by Malinowski [9] about the institution that the presence of a group of people who are tied to the specific natural environment, which produce and use this type of equipment specific material, have a certain knowledge in using and working environment with the equipment above, has the typical language that would allow them to establish cooperation, has legal rules that govern their behavior, and have shared beliefs and certain values. Or in brief, an institution consists of: personnel, material culture, knowledge, rules, beliefs, and charter.

\section{B. Aisatsu as Phatic Communion}

Aisatsu as Phatic Communion is important to the Japanese. Sometimes the Japanese society judge a person from how people greet. Aisatsu is also viewed as the norms prevailing in the society in Japan.. Mizutani (1995) said that aisatsu is a phrase that is used to establish the relationship between the human, or to maintain good relations of our fellow human beings, or as an expression in conveying language, and not just convey emotion or information through language. Which become the focus is the expression of the preamble itself which is placed on the context-social context.

Based on the placement on the context-social context, the preamble can be addressed to people who are known, want the known and unknown in one community said that it has norm of the same language. Making small talk with people who do not know or want to know the aims to open up or begin to develop a social relationships among them. This process can be said as the approach of social relations between speakers. On the other hand, the activity of the niceties for people who are already known the purpose is solely to maintain the relationship that has been ever constructed. This process is referred to as the process of retention or maintenance of the closeness of the relationship social between speakers.

\section{METHODS}

Through the survey, the data containing the conversation colloquial of Japanese language that contains the practices of the ado. The process consists of: (1) collecting data; (2) identifying data (data that contains the practices of the ado); (3) classifying data, (4) transcribing data; and (5) interpreting data.

Subject of the research is Japanese speakers in Surabaya. The research object is the speech of pleasantry as greeting, pleasantries as a courtesy and pleasantries as a courtesy. The data collection instrument are documentation and observation. The data were analyzed using descriptive qualitative techniques; description of the findings and description of the conclusion.

\section{DISCUSSION}

Preamble (tatemae) consists of greetings, manners, and politeness. These components constitute a single package which will be explained one by one as follows.

\section{A. Preamble (tatemae) as Greetings}

Tegur sapa (greetings/aisatsu) is a series of phrases or speech acts used in the beginning of the meeting or when meeting with someone. There are many ways on how Japanese people greet. There are people who pronounce greetings attributed to weather, health or greetings. Use of speech is thus necessarily related to the greetings or opening communication. Greetings can be done by using the following speech:

1. Ohayou Gozaimasu "Good Morning",

2. Konnichiwa "Good afternoon",

3. Konbanwa "Good Evening",

4. Ogenki desu ka "What's up",

5. Kуоu wa ii tenki desu ne "the Day is bright, isn't it?"; etc.

Each can be answered as follows:

1. Ohayou gozaimasu "Good Morning",

2. Konnichiwa "Good afternoon",

3. Konbanwa "Good Evening",

4. Okagesama de, genki desu "Thanks to your prayer, I am fine",

5. Hai, sou desu "Yes".

In addition there are people who exchanged greetings with how to give attention, by saying something that is being experienced or done partner he said, for example:

6. Ojama shimasu ka "Is it annoying?", 
7. Odekake desu ka "Do you wanna go?"

8. Dochira e odekake desu ka "Where are you going?", etc.

In this connection the provision of attention can also be used as an opener of communication. As for the response given as the following:

6a. Iie, daijoubu desu "No, nothing",

7a. Hai/Ee "Yes,

8a. Ee, chotto sono hen made "Yes, i want to go to there"

Phrases of greetings is used only to keep the situation in order to avoid the silence of the communication in between the speakers. The function of the expression is double, as the opening of the contact communication and/or retention of social relations ever to exist.

Greetings in the preamble part preamble routine that is indispensable in social life. For example in the relationship of family members/groups are always kept compatible, such as the following:

9. A: Itte kimasu "I go first"

B: Itte rasshai "Yes, goodbye"

In this case the $\mathrm{A}$ is $\mathrm{A}$ member of the family/group that will be out of the house (work, school and so on), and B is the person who left to go (are at home). Similarly, when you go home, A would say

\section{A: Tadaima "I come/I'm home"}

\section{B: Okaerinasai" Welcome back"}

\section{B. Further Ado (tatemae) as a Courtesy}

Politeness (courtesy) is a phrase or action which shows respect (comity) and kindness to someone. Kindness is defined as the value of conduct that are accepted in the conventions of society. In linguistic point of view, expression or act of courtesy often arise, such as the phrase excuse me, apologetic, invitation, thank you, and saying goodbye. This limitation implies that the expression or act of courtesy not just to start a communication but also an end to that conversation. Manners as the opening or closing of communication can be also called karma or social customs. The expression shitsurei shimasu, "Excuse me" can be used by guests when going in the house or office. The essence of manners lies in the value of ethics normative. Expression of manners of distribution as the opener for example the expression of apology and invitation as follows:

11. Osoku natte sumimasen "Sorry I'm late"

12. Chotto ukagaimasu "Sorry, want to ask"

13. Douzo oagari kudasai "Please enter (up)"

14. Chotto omachi kudasai "Please wait a minute"

While as the cover of each thank you, apology, invitation, saying goodbye:

15. Osewa ni narimashita "Thank you for your help"
16. Iro-iro arigatou gozaimashita "Thank you very much"

17. Osaki ni shitsurei shimasu "I'm Sorry I'll leave her to you"

18. Itsu demo kite kudasai "Please come anytime you want"

19. Mata ne "See you again"

Thus, it is clearly different when comparing with the greetings which is as the start of a communication. Greetings may be called manners. Greetings to the civil manners surely is different with regards to the poor area.

The examples outlined above are also examples of the manners that are associated with congratulations, invitation, prohibition, rejection, humiliation of heart, and attention as follows:

\section{Omedetou gozaimasu "Congratulations"}

21. Ocha demo nomimasenka "How about a drink of tea"

22. Okamainaku "Don't bother"

23. A: Kireina imouto san deu ne "Your little sister is so pretty"

B: Iie, sore hodo demo arimasen. "Not really"

24. Minasama ni yoroshiku "Greetings to all"

25. Itsu tsukimashita $\mathrm{ka}$ "When are you coming?"

26. O ki o tsukete kudasai "be careful"

27. O karada ni taisetsuni "take care of yourself"

28. O daijini "hopefully a speedy recovery"

The only difference speech is, it is optional for speakers, meaning that people can congratulate or not, to invite to drink or not, and so on.Therefore, the speech was also related to the hospitality subjective that is manners-oriented initiative speakers.

\section{Pleasantries as Politeness}

Convivial is a phrase used to recognize a person (selfidentification), memory of events experienced or seen together (memorization) or to please the hearts of the hearer. The activity of the suave overcome the realm of greetings and manners without losing the value of courtesy. Activities suave is mostly found in a situation such as a casual chat during coffee break, reunion, and others.

In the lowest levels of hospitality, it is shown by the desire to communicate and at the same time as the opening of communication. Furthermore, in a deeper level, the hospitality shown by being attached to each other and harmony.

The phrase convivial that can be used to recognize a person (self-identification), for example regarding the self as name, place of residence, origin or native to the area, then it can also be shifted to topics more widely. Expression of welcoming can be used to describe the memories of the meeting, education, work, place of residence.

Examples of speech here shows the reality of the speech: 
29. Hajimemashite. Watashi wa Suzuki desu. Dozo yoroshiku. "Hi, I'm Suzuki, Pleased to meet with you".

30. Anata wa kono machi de goryoshin to issho ni sunde imasu ka. "Do you live in the city with your parents?"

31. Kyodai wa nannin desu ka. "How many brothers do you have?"

32. Anata wa nanbanme desu ka. "What is your number?"

33. Ohisashiburi desu ne. "Long time no see"

34. Yoshida sensei wa mada ooshieni natte imasu ka. "Is Mr. Yoshida still teaching?"

Creating the feelings of other people to be happy is the actual purpose on how the relationship of friendship or kinship can be maintained and spared from conflict or opposition. The principle of harmony (harmony) is a reflection of the components of suave.

\section{CONCLUSION}

From the above description it can be concluded that the use of aisatsu (greetings) are very important things that should be done by the Japanese society as a platitude (Phatic Communion). Aisatsu can open one's heart and draw closer to the hearer when interacting as a preamble (tatemae). In the context of the Japanese language, aisatsu is often used when dealing with fellow humans (human relations) in the daily life of Japanese people. Based on the placement on the social context, the preamble can be addressed to people who are known, want the known and unknown in one community said that it has norm of the same language. Making small talk with people who do not know or want to know the aims to open up or begin to develop a social relationships among them. This process can be said as the approach of social relations between speakers. On the other hand, the activity of the niceties for people who are already known the purpose is solely to maintain the relationship that has been ever constructed.

Using ado (tatemae) as greetings, manners, suave aims to the harmonization means to maintain and foster social relationships among speakers.

\section{REFERENCES}

[1] C. Geertz, The Interpretation of Cultures. New York: Basic Books Inc., 1973.

[2] N. Bonvillian, Language, Culture and Communication: The Meaning of Messages. New Jersey: Prentice Hall Inc., 1977.

[3] O. Mizutani and N. Mizutani, How to be Polite in Japanese. Tokyo: The Japan Times, 1987.

[4] N. K. Gakkai, Nihongo Kyouiku Jiten. Tokyo: Daishuukan Shoten, 1997.

[5] M. Koyama, Tadashii Nihongo Jiten. Hiroshima: Taizoku Shuppan, 2003.

[6] A. Moeliono, The Great Dictionary of the Indonesian Language. Jakarta: Department of Education, 1988.

[7] B. Malinowski, "The Problem in Primitive Language," in The Meaning of Meaning. vol. Supplements I, C. K. Ogden and I. A. Richards, Eds., ed New York: A Harvest Book, 1923, pp. 296-336.

[8] D. Crystal, A Dictionary of Linguistics and Phonetics. New York: Blackwell Publishers, 1991.

[9] B. Malinowski, "The Group and the Individual in Functional Analysis," American Journal of Sociology, vol. 44, pp. 938-964, 1939. 